\title{
Periodontal findings in patients with leprosy
}

\author{
B BOMBACH \& P REICHART
}

Abteilung für zahnärztliche Chirurgie/Oralchirurgie, Polikliniken für Zahn-, Mund- und Kieferheilkunde- Nord, Föhrerstraße 15, Freie Universität Berlin, Berlin, West Germany

\section{Accepted for publication 28 October 1986}

\begin{abstract}
Summary The periodontal status of 110 patients with leprosy and 34 healthy controls was studied using periodontal indices. Comparison of the different periodontal indices between controls and patients showed significantly higher values for some of these indices in the latter group. Limitation of oral hygiene due to deformation or mutilation of fingers and hands had no statistically significant correlation to the periodontal findings. Indices for plaque and calculus, factors contributing to the degree of gingival and periodontal inflammation, were higher in the group of patients even if the same degree of inflammation was present in both groups.

A probable influence of the anti-leprosy-therapy may be considered. Comparably low values for the gingival index and the sulcus fluid rate for those patients treated with clofazimine may indicate an anti-inflammatory effect of this specific therapy at the gingivo-periodontal complex.

Poor oral hygiene due to lack of motivation and/or a generally reduced status of health in leprosy patients must be considered as one of the main causes of periodontal disease.
\end{abstract}

\section{Introduction}

Oral manifestations of leprosy have been reported in the literature. ${ }^{1-11}$ Hard and soft oral structures may be involved. Dental changes were described as odontodysplasia leprosa. ${ }^{12}$ Skeletal manifestations were reported as facies leprosa ${ }^{3,4}$ Soft tissue lesions may involve a reduced sensitivity of the oral mucosa, leproma formation, ulceration and complete loss of oral soft structures such as the soft palate. ${ }^{2,5,6,8-10}$

Various authors have reported on chronic periodontitis in leprosy patients. ${ }^{1,5,6,13-19}$ Different causes for periodontal destruction in leprosy patients have been suspected. Poor oral hygiene due to lack of motivation or disability resulting from advanced mutilation of fingers and hands has been mentioned. ${ }^{7}$ 
Also unbalanced muscular activity due to facial paralysis involving the portio minor of the trigeminal nerve had been considered. ${ }^{5}$ Most of the reports on periodontal disease in leprosy were merely descriptive lacking systematical criteria. Only recently have studies on the periodontium of leprosy patients been reported using accepted periodontal indices. ${ }^{17,19}$

The aim of the present study was to examine periodontal conditions in leprosy patients by using periodontal indices and parameters relating to periodontal disease. All values and measurements were compared to those of a group of healthy controls. Parameters such as age, oral hygiene habits, anti-leprosytherapy as well as limitation of oral hygiene due to deformation of hands were specifically considered.

\section{Material and methods}

One hundred and ten randomized leprosy patients were examined for their periodontal status at the McKean Rehabilitation Institute in Chiang Mai, Thailand. Thirty-four healthy controls were examined at the Faculty of Dentistry, Chiang Mai University, Chiang Mai, Thailand. All patients were examined using a dental unit with artificial light. Age of the patients, type of leprosy according to the classification of Ridley-Jopling ${ }^{20}$ anti-leprosy-therapy and duration were recorded. The latest bacterial index (BI) was determined to reveal the stage of disease. Three age groups were formed: group 1 (under 30 years), group 2 (30-60 years), group 3 (over 60 years).

The degree of gingival and periodontal inflammation was determined using the sulcus fluid flow rate (SFFR) according to the modified intracrevicular method described by Löe \& Holm-Pedersen. ${ }^{21}$ The SFFR was determined from the gingival sulcus of the left maxillary central incisor ${ }^{21}$ and the right mandibular first premolar. ${ }^{44}$ In addition the gingival index $(\mathrm{GI})^{22,23}$ was determined. The oral hygiene status was evaluated using the 'Oral Hygiene Index Simplified' (OHIS). ${ }^{24}$ This index is a combination of the plaque index and the calculus index. Gingival index and oral hygiene index indices were determined at the oral and facial surfaces of 6 teeth according to Ramfjord ${ }^{25}$ (right maxillary first molar (16), left maxillary central incisor (21), left maxillary first premolar (24), right first mandibular molar (36), left mandibular central incisor (41), right mandibular first premolar (44)). For the same teeth the depth of periodontal pockets was recorded using a Michigan-O-periodontal probe and measurements were recorded in millimeters. Gingival retraction was measured from the cementoenamel junction to the gingival margin $(\mathrm{mm})$ in all existing teeth. Tooth mobility of all teeth was recorded on a scale of $0-3$ and decayed, missing and filled teeth (DMFT-Index) were also recorded.

In order to evaluate the ability for oral hygiene, hands and fingers were examined for leprosy specific deformations. Four grades of mutilation were recorded: 
grade 0 : both hands intact;

grade 1: unilateral deformation (claw hand and/or loss of finger segments); grade 2: bilateral moderate deformations (claw hand, loss of 1 or 2 finger segments);

grade 3: bilateral severe deformations (loss of more than two segments of fingers to loss of all fingers).

Mode and frequency of oral hygiene was also recorded.

All periodontal parameters and values were correlated to age, oral hygiene habits, anti-leprosy-therapy and grade of mutilation of fingers and hands. Data were computerized and tested for significant correlations. The oral hygiene index was correlated to the degree of gingival and periodontal inflammation (SFFR, GI).

Additionally 34 matched pairs were formed by combining each member of the control group with one leprosy patient of the same age and sex. That was done in order to avoid mistakes from the possible dependence of several parameters from age and sex. Again data were compared by using the Student's T-test on a 95\% confidence level. Averages for the group of patients were calculated from the individual averages of all parameters examined. These values were compared to those of the control group using the Student's T-test on a 95\% confidence level.

\section{Results}

Eighty of the 110 leprosy patients were males (range 16-92 years, average age $55 \cdot 2$ years). Of the 30 females the average age was 53.5 years (range $23-82$ years). Thus the overall average age of 110 leprosy patients was 54.7 years. Eleven patients were recorded in age group 1 (under 30 years), in age group 2 (30-60 years) there were 61 patients and in age group 3 (over 60 years) 38 patients. According to the classification of Ridley \& Jopling ${ }^{20}, 62$ patients $(56 \cdot 4 \%)$ were of the lepromatous type of leprosy (LL), $14(12 \cdot 7 \%)$ were of the borderline lepromatous type (BL), 1 $(0 \cdot 9 \%)$ was of the borderline type (BB), $29(26 \cdot 3 \%)$ were of the borderline tuberculoid type (BT), and 4 patients (3.6\%) were of the tuberculoid type (TT).

The average duration of leprosy was 23.6 years (range from 2 to 64 years). The average period of therapy was 13.8 years ( 2 weeks to 50 years). In 91 patients $(82.7 \%)$ the bacterial index (BI) was negative; it was positive in 19 patients $(17 \cdot 3 \%)$. Eighty-one of the negative cases were treated with Dapsone ${ }^{\circledR}$ (DDS, 50$100 \mathrm{mg}$ per day). Thirteen patients with a positive BI received a combination therapy of DDS and clofazimine (Lamprene ${ }^{\circledR}$ ); 6 patients received clofazimine as a monotherapy. Ten patients with a negative bacterial index did not receive any anti-leprosy-therapy.

Examination of fingers and hands revealed a disease specific spectrum of changes. Twenty-nine patients $(26.4 \%)$ had no changes (grade 0$)$. Thirty-two 
patients $(29.1 \%)$ showed deformations of one hand of varying severity while the other hand was without any changes (grade 1). In 49 patients $(44.5 \%)$ both hands were affected, of these 34 cases $(30.9 \%)$ revealed claw hand with loss of one or two digital segments (grade 2). Fifteen patients showed severe mutilations of fingers and hands (grade 3 ). Only 98 patients could give information about their oral hygiene habits, which included use of a toothbrush by 74 patients $(75.5 \%)$ and use of toothpicks by 38 patients $(38 \cdot 8 \%)$. Fingers were used by only 7 patients $(7 \cdot 1 \%)$. Twenty-four of 98 patients (24.5\%) did not perform any oral hygiene, 25 patients $(25.5 \%)$ brushed their teeth once a day, $36(36.7 \%)$ brushed twice a day and 13 $(13.2 \%)$ brushed three to five times a day. Of those patients who did not perform any oral hygiene $17(70 \cdot 8 \%)$ were over 60 years old (44.7\% of this age group), $88.5 \%$ of the patients of age group 2 and all patients of age group 1 performed oral hygiene at least once a day. At an average for all 98 patients oral hygiene was performed 1.41 times per person per day. Averages for all periodontal parameters of the entire group of patients were:

Sulcus fluid flow rate (SFFR):

Gingival index (GI):

Calculus index (OHI calculus):

Plaque index (OHI plaque):

Oral hygiene index (OHI-S):

Pocket depth:

Tooth mobility:

Gingival retraction:

DMFT-Index:

$$
\begin{aligned}
& 2.07 \pm 1.64 \mathrm{~mm} \\
& 1.35 \pm 0.39 \\
& 0.68 \pm 0.52 \\
& 0.95 \pm 0.54 \\
& 1.63 \pm 0.90 \mathrm{~mm} \\
& 2.61 \pm 0.59 \mathrm{~mm} \\
& 0.39 \pm 0.49 \\
& 1.89 \pm 1.95 \mathrm{~mm} \\
& 10.64 \pm 9.18
\end{aligned}
$$

Tooth mobility was observed in more than $50 \%$ of all teeth in 24 patients $(21 \cdot 8 \%)$. In 52 patients $(47 \cdot 3 \%)$ less than $50 \%$ of the teeth were mobile. No mobility of teeth was recorded in 34 patients (30.9\%).

Gingival retraction was seen as a generalized symptom in 61 patients $(55 \cdot 5 \%)$; whereas it was found as a localized phenomenon in only 23 patients $(20.9 \%)$. In 26 patients $(23.6 \%)$ no retraction was recorded. Correlation of the periodontal values with age groups, frequency of oral hygiene, anti-leprosy-therapy and degree of mutilation are summarized in Tables $1-4$.

Some periodontal indices and measurements revealed a correlation to age. Significant differences were found for the calculus index $(p=0.009)$, tooth mobility $(p=0.0008)$, gingival retraction $(p=0.0000)$ and DMFT index $(p=0.0000)$ (Table 1). Correlation of results to frequency of oral hygiene showed significant differences between the group of patients without any oral hygiene and those patients performing oral hygiene measures once a day (Table 2). It seemed to be of less importance whether oral hygiene was performed once, twice or more than two times per day since no significance was seen between these groups. Correlation of periodontal indices and mode of therapy showed that all values of those treated with DDS and clofazimine in combination and some of those 
Table 1. Periodontal values in relation to age

\begin{tabular}{lcccc}
\hline Age & & & & \\
\hline SFFR $(\mathrm{mm})$ & 1.32 & 1.75 & 2.25 & 2.07 \\
Gingival-Index & 1.23 & 1.33 & 1.41 & 1.35 \\
Calculus-Index*1 & 0.30 & 0.65 & 0.83 & 0.68 \\
Plaque-Index & 0.84 & 0.83 & 1.18 & 0.95 \\
OHI-S & $1 \cdot 14$ & 1.48 & 2.01 & 1.63 \\
Pocket depth & 2.43 & 2.69 & 2.54 & 2.61 \\
Tooth mobility*2 & 0.03 & 0.33 & 0.59 & 0.39 \\
Gingival retraction*3 & 0.21 & 1.68 & 2.71 & 1.89 \\
DMFT-Index*4 & 2.82 & 7.84 & 16.55 & 10.64 \\
No. of cases & 11 & 61 & 38 & 110 \\
& & & & \\
\hline
\end{tabular}

* significance: $1, \dot{p}=0.0092 ; 2, p=0.0008 ; 3, p=0.0000 ; 4$, $p=0 \cdot 0000$.

+ Total refers to the average values of the entire group of patients mentioned in the text.

Table 2. Periodontal values in relation to frequency of oral hygiene

\begin{tabular}{|c|c|c|c|c|c|}
\hline Oral hygiene & No & lx/day & $2 x /$ day & $3-5 x /$ day & Total + \\
\hline $\operatorname{SFFR}(\mathrm{mm}) * 1$ & $3 \cdot 21$ & 1.99 & $1 \cdot 43$ & $2 \cdot 38$ & $2 \cdot 07$ \\
\hline Gingival-Index*2 & $1 \cdot 63$ & $1 \cdot 33$ & $1 \cdot 24$ & $1 \cdot 29$ & $1 \cdot 35$ \\
\hline Calculus-Index*3 & $1 \cdot 24$ & $0 \cdot 61$ & $0 \cdot 48$ & $0 \cdot 71$ & $0 \cdot 68$ \\
\hline Plaque-Index*4 & $1 \cdot 61$ & 0.97 & 0.66 & 0.71 & 0.95 \\
\hline OHI-S*5 & $2 \cdot 85$ & $1 \cdot 59$ & $1 \cdot 15$ & $1 \cdot 41$ & $1 \cdot 63$ \\
\hline Pocket depth (mm) & $2 \cdot 79$ & $2 \cdot 53$ & $2 \cdot 61$ & $2 \cdot 73$ & $2 \cdot 61$ \\
\hline Tooth mobility*6 & 0.78 & $0 \cdot 32$ & $0 \cdot 30$ & $0 \cdot 19$ & $0 \cdot 39$ \\
\hline Gingival retraction*7 & $2 \cdot 44$ & $2 \cdot 01$ & $1 \cdot 47$ & $1 \cdot 74$ & 1.89 \\
\hline DMFT-Index*8 & $20 \cdot 16$ & $8 \cdot 12$ & $6 \cdot 44$ & $7 \cdot 00$ & $10 \cdot 64$ \\
\hline No. of cases & 24 & 25 & 36 & 13 & 98 \\
\hline
\end{tabular}

* significance: $1, p=0.0100 ; 2, p=0.0061 ; 3, p=0.0000 ; 4$, $p=0.0000 ; 5, p=0.0000 ; 6, p=0.0032 ; 7, p=0.0000 ; 8, p=0.0000$.

+ Total refers to the average values of the entire group of patients mentioned in the text.

treated with clofazimine alone were below the average values of the entire group. Values of patients who received only DDS or no therapy at all were above the average level of the whole group. Differences were statistically significant for the sulcus fluid flow rate $(p=0 \cdot 04)$, (Table 3$)$. Table 4 shows the correlation of periodontal values and the degree of finger mutilation. Although some values were higher in grade 3 compared to grade 0,1 or 2 no statistically significant 
Table 3. Periodontal values in relation to therapy

\begin{tabular}{lccccc}
\hline Therapy & DDS + B 663 & B 663 & DDS & No & Total† \\
\hline SFFR (mm)*1 & 1.14 & 1.63 & 2.22 & 2.94 & 2.07 \\
Gingival-Index & 1.18 & 1.42 & 1.36 & 1.46 & 1.35 \\
Calculus-Index & 0.42 & 0.52 & 0.73 & 0.69 & 0.68 \\
Plaque-Index & 0.95 & 1.20 & 0.91 & 1.33 & 0.95 \\
OHI-S & 1.37 & 1.72 & 1.64 & 2.02 & 1.63 \\
No. of cases & 13 & 6 & 81 & 10 & 110 \\
\hline
\end{tabular}

* significance: $1, p=0 \cdot 04$.

+ Total refers to the average values of the entire group of patients mentioned in the text.

Table 4. Periodontal values in relation to mutilation of fingers

\begin{tabular}{lccccc}
\hline Deformation & Grade 0 & Grade 1 & Grade 2 & Grade 3 & Total* \\
\hline SFFR (mm) & 2.25 & 1.87 & 2.14 & 2.00 & 2.07 \\
Gingival-Index & 1.13 & 1.35 & 1.36 & 1.40 & 1.35 \\
Calculus-Index & 0.52 & 0.71 & 0.74 & 0.78 & 0.68 \\
Plaque-Index & 1.05 & 0.89 & 0.94 & 0.95 & 0.95 \\
OHI-S & 1.58 & 1.60 & 1.67 & 1.73 & 1.63 \\
Pocket depth (mm) & 2.51 & 2.58 & 2.64 & 2.83 & 2.61 \\
Tooth mobility & 0.25 & 0.40 & 0.45 & 0.51 & 0.39 \\
Gingival retraction & $1 \cdot 19$ & 2.00 & 3.34 & 2.08 & 1.89 \\
DMFT-Index & 9.80 & 10.08 & 11.48 & 11.20 & 10.64 \\
No. of cases & 29 & 32 & 34 & 15 & 110 \\
& & & & & \\
\hline
\end{tabular}

* Total refers to the average values of the entire group of patients mentioned in the text.

differences could be found. In Figure 1 the correlation between the OHI-S and the gingival index is presented. In Figure 2 the correlation between the OHI-S and the sulcus fluid flow rate is seen. Statistical differences were found between SFFR, $\mathrm{OHI}-\mathrm{S}$ and the degree of gingival inflammation (Figures 1 and 2).

\section{CONTROL GROUP}

In the control group of 34 healthy patients 13 were males and 21 were females between 19 and 67 years of age (males 19-67, females 20-64). The average age of the whole group was $40 \cdot 3$ years (males $41 \cdot 8$, females $39 \cdot 3$ years). Nine people were of age group 1, 22 of age group 2 and 3 of age group 3 . All 34 patients performed oral hygiene. Three performed oral hygiene once a day, 15 twice a day and one patient three times a day. An average frequency of oral hygiene of 1.9 times per 


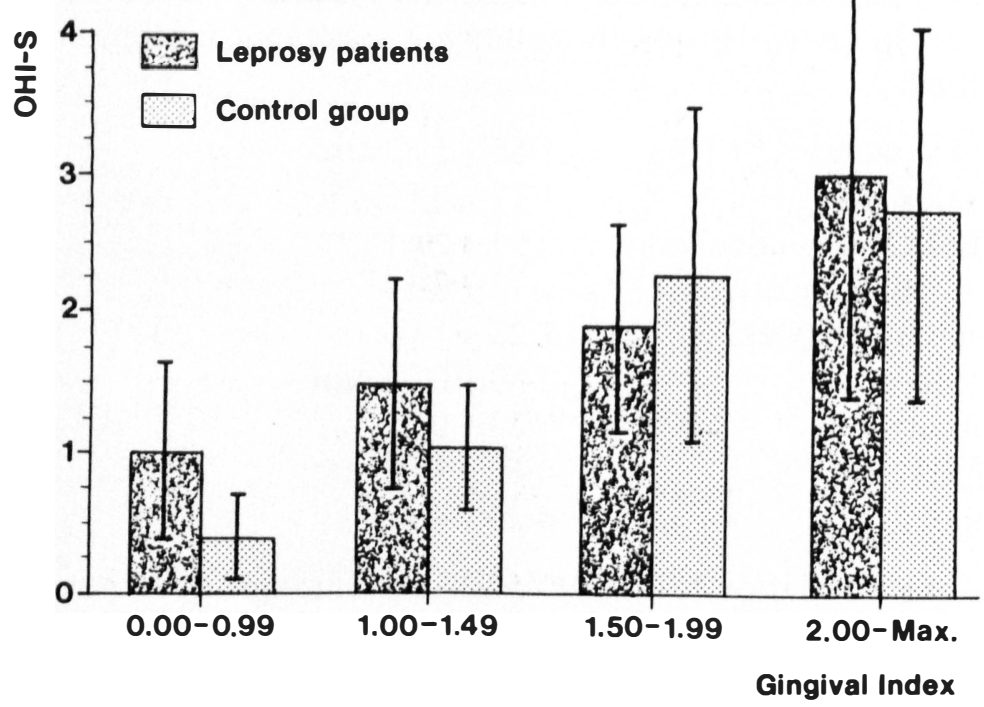

Figure 1. Comparison between patients and controls relating to gingival index (GI) and OHI-S. Results of GI have been split up in 4 ranges. Bar represents standard deviation.

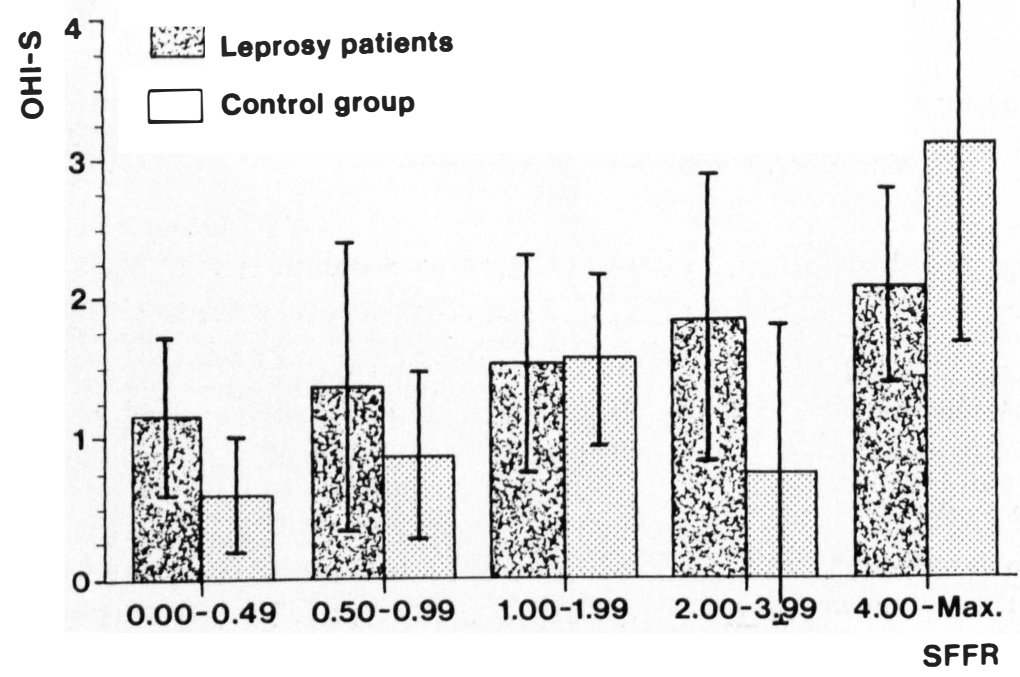

Figure 2. Comparison between patients and controls relating to SFFR and OHI-S. Results of SFFR have been split up in 5 ranges. Bar represents standard deviation. 
person and day was calculated. Thirty-two patients (94.1\%) used a toothbrush and of these 15 additionally used toothpicks. Fingers were only applied by two patients. For the control group the following averages for all periodontal values were obtained:

Sulcus fluid flow rate (SFFR): $\quad 1.66 \pm 1.82 \mathrm{~mm}$

Gingival index (GI): $\quad 1 \cdot 17 \pm 0.52$

Calculus index (OHI-calculus): $\quad 0.55 \pm 0.61$

Plaque index (OHI-plaque): $\quad 0.73 \pm 0.50$

Oral hygiene index (OHI-S): $\quad 1.28 \pm 1.03$

Pocket depth:

$2 \cdot 59 \pm 0.76 \mathrm{~mm}$

Tooth mobility:

$0 \cdot 23 \pm 0 \cdot 37$

Gingival retraction:

DMFT-index:

$0.62 \pm 1.00 \mathrm{~mm}$

$4 \cdot 20 \pm 4 \cdot 42$

In Figure 1 correlation between $\mathrm{OHI}-\mathrm{S}$ and the gingival index is also presented for the control group. Statistical differences between the OHI-S and the degree of gingival inflammation was found $(p=0 \cdot 0000)$. In Figure 2 the correlation between the OHI-S and the sulcus fluid flow rate is shown. Figures 1 and 2 also allow for a comparison of the patients' values to those of the control group. At the same degree of gingival inflammation the values for the leprosy patients were usually higher than those of the controls. Obviously the same degree of the gingival inflammation in the leprosy patients was only attained if a more heavy accumulation of plaque and calculus was present. Table 5 describes the comparison of all averages of the leprosy patients and the controls. All values of the leprosy patients were higher than those of the controls. Significant differences

Table 5. Averages of the groups

\begin{tabular}{|c|c|c|c|}
\hline & Group of patients & Controls & $\begin{array}{c}\text { Group of matched } \\
\text { pairs }\end{array}$ \\
\hline SFFR & $2 \cdot 07 \pm 1 \cdot 64$ & $1 \cdot 56 \pm 1 \cdot 82$ & $1 \cdot 89 \pm 1 \cdot 66$ \\
\hline Gingival-Index & $1 \cdot 35 \pm 0 \cdot 39$ & $1.17 \pm 0.52$ & $1 \cdot 33 \pm 0 \cdot 36$ \\
\hline Calculus-Index & $0.68 \pm 0.52$ & $0.55 \pm 0.61$ & $0.55 \pm 0.60$ \\
\hline Plaque-Index* & $0.95 \pm 0.54$ & $0.73 \pm 0.50$ & $0.96 \pm 0.49$ \\
\hline OHI-S & $1 \cdot 63 \pm 0 \cdot 90$ & $1 \cdot 27 \pm 1.03$ & $1.51 \pm 0.87$ \\
\hline Pocket depth & $2.61 \pm 0.59$ & $2.59 \pm 0.76$ & $2.65 \pm 0.67$ \\
\hline Tooth mobility* & $0.39 \pm 0.49$ & $0.23 \pm 0.37$ & $0 \cdot 25 \pm 0 \cdot 40$ \\
\hline Gingival retraction $(\mathrm{mm})^{*}$ & $1.89 \pm 1.95$ & $0.62 \pm 1.00$ & $1.04 \pm 1.68$ \\
\hline DMFT-Index* & $10 \cdot 64 \pm 9 \cdot 18$ & $4 \cdot 20 \pm 4 \cdot 42$ & $6 \cdot 12 \pm 6 \cdot 78$ \\
\hline No. of cases & 110 & 34 & 34 \\
\hline
\end{tabular}

* statistically significant $(p<0.05)$. 
were found for the plaque index, tooth mobility, gingival retraction and DMFTindex. Also the matched pairs showed some higher averages for the leprosy patients than for the controls. However, no statistically significant differences were found.

\section{Discussion}

Probable causes for the higher periodontal indices within the group of leprosy patients after elimination of the age factor and formation of matched pairs were: 1, the oral hygiene habits; 2 , limitation of oral hygiene due to finger and hand deformation; and 3, an influence of the anti-leprosy-therapy.

Evaluation of the different indices in correlation to the degree of finger mutilation showed only minor differences which were not significant between patients who had no deformations and patients with changes of grade 3 . Thus, deformation of fingers and hands may not be considered a principle cause for periodontitis in leprosy patients. In contrast, correlation between periodontal indices and oral hygiene was statistically significant for almost all indices. In this regard it was of no importance whether the patients brushed their teeth once or several times per day. A continuous regular oral hygiene was more important. Within the group of leprosy patients, frequency of oral hygiene was calculated with 1.41 times per person per day. This figure was considerably lower compared to the frequency within the control group ( 1.9 times per person per day). It was found that $70.8 \%$ of the leprosy patients who did not perform any oral hygiene were older than 60 years. According to these findings poor oral hygiene within the group of leprosy patients may be considered one of the main causative factors for the comparatively higher periodontal indices. Deformations of fingers and hands seem to be less important than lack of motivation for oral hygiene and a reduced health status due to high age.

Comparison of the different periodontal findings with each other showed a positive correlation between the oral hygiene indices (Calculus index, Plaque index, OHI) and the degree of gingival and periodontal inflammation (GI, SFFR). These findings have also been made in various studies on nonleprosy patients ${ }^{21,26-32}$.

Of interest was that, for the same degrees of gingival inflammation, values for factors causing inflammation like plaque and calculus were usually higher within the group of leprosy patients compared to the control group (Figures 1 and 2). This finding was unusual and difficult to explain. A probable anti-inflammatory influence of the leprosy therapy was suspected. Clofazimine in particular has been considered to have an anti-inflammatory effect. ${ }^{32}$ Correlation between periodontal indices and the different forms of therapy showed that values in patients who received clofazimine as a monotherapy or in combination with DDS were always below the average of the entire group of leprosy patients. An anti-inflammatory 
effect of clofazimine on gingiva and periodontium however could not clearly be deduced from the results because an influence on the periodontal values of the age of the patients has also to be considered. Also most of the patients receiving clofazimine were of younger age while some old patients whose acute phase of leprosy was over for many years did not receive any therapy.

While the anti-inflammatory effect of anti-leprosy-therapy may exert a certain effect at the gingival-periodontal complex immune dysfunctions in patients with leprosy have also been suggested as an etiological factor. As in the present study, Subramaniam et al. ${ }^{19}$ have observed relatively low degrees of gingival inflammation compared to a rather high plaque index. This phenomenon was explained as an inability of leprosy patients to respond to certain antigens.

While periodontitis in leprosy is principally comparable to that of the nonleprosy patient an anti-inflammatory effect of anti-leprosy-therapy may be involved as well as changes in the immune response of leprosy patients. Further immunological studies in periodontitis of leprosy patients are needed.

\section{References}

' Prejean BM. Oral aspects of leprosy. J Am Dent Ass, 1936; 17: 1030-2038.

2 Prejean BM. Oral manifestations in leprosy. Int J Orthodont, 1936; 22: 1189-94.

3 Møller-Christensen V, Bakke SN, Melsom RS, Waaler E. Changes in the anterior nasal spine and the alveolar process of the maxillary bone in leprosy. Int J Lepr, 1952; 20: 355.

${ }^{4}$ Møller-Christensen V. Changes in the anterior nasal spine and the alveolar process of the maxilla in leprosy. Int J Lepr, 1974; 42: 431-5.

${ }^{5}$ Lighterman I, Watanabe Y, Hidaka T. Leprosy of the oral cavity and adnexa. Oral Surg, 1962; 15: 1178-94.

${ }^{6}$ Epker BN, Via WF. Oral and perioral manifestations of leprosy. Oral Surg, 1969; 28: 342-7.

7 Werner R. Lepra im Mund-, Kiefer- und Gesichtsbereich. Dtsch Zahnärztl Z, 1973; 28: 64-73.

${ }^{8}$ Southam JC, Venkataram BK. Oral manifestations of leprosy. Brit J Oral Surg, 1973; 10:272-9.

9 Reichart P. Pathologic changes in the soft palate of lepromatous leprosy. Oral Surg, 1974; 38: 898-904.

10 Reichart P. Facial and oral manifestations in leprosy. Oral Surg, 1976; 41: 385-99.

"Manson-Bahr PEC, Apted FIC. Mansons tropical diseases, 18th ed. Baillière Tindall, London 1983.

12 Danielsen K. Odontodysplasia leprosa in Danish mediaeval skeletons. Tandlaegebladet, 1970; 74: $606-25$.

13 Itakura T. The histo-pathological studies in teeth of lepers, especially on the dental pulp and gingival tissues. Trans Soc Path Jap, 1940; 30: 357-67.

14 Mathis H. Die Lepra im Arbeitsbereich des Stomatologen. Dtsch Zahn-Mund-Kieferheilk, 1955; 21: 280-6.

15 Sala HL. Leprosy of the mouth: report of a case. Oral Surg, 1957; 10: 610-11.

${ }^{16}$ Fitch HB, Alling CC. Leprosy: oral manifestations. J Periodont, 1962; 33: 40-44.

17 Reichart P, Anantasan T, Rezink G. Gingiva and periodontium in lepromatous leprosy. $J$ Periodont, 1976; 47: 455-60.

18 Subramaniam K, Marks SC. Alveolar bone loss in leprosy, a clinical and radiological study. Lepr Rev, 1978; 49: 287. 
19 Subramaniam K, Marks SC, Seang Hoo Nah. The rate of loss of maxillary anterior alveolar bone hight in patients with leprosy. Lepr Rev, 1983; 54: 119-27.

${ }^{20}$ Ridley DS, Jopling WH. Classification of leprosy according to immunity. Int J Lepr, 1966; 34: 255-73.

${ }^{21}$ Löe H, Holm-Pedersen P. The absence and presence of fluid from normal and inflamed gingiva. Periodont, 1965; 3: 171-7.

22 Löe H, Silness J. Periodontal disease in pregnancy, I. Prevalence and severity. Acta Odont Scand, 1963; 21: 533-51.

${ }^{23}$ Löe $\mathrm{H}$. The gingival index, the plaque index and the retention index system. J Periodont, 1967; 38: 610-16.

${ }^{24}$ Greene JC, Vermilliom JR. The simplified oral hygiene index. J Am Dent Ass, 1964; 68: 7-13.

${ }^{25}$ Ramfjord SP. Indices for prevalence and incidence of periodontal disease. J Periodont, 1959; 30: $51-9$.

${ }^{26}$ Brill N. Gingival conditions related to flow of tissue fluid into gingival pockets. Acta Odont Scand, 1960; 18: 421-46.

${ }^{27}$ Mann WV. The correlation of gingivitis, pocket depth and exsudate from the gingival crevice. $J$ Periodont, 1963; 34: 379-87.

${ }^{28}$ Egelberg J. Gingival exsudate measurements for the evaluation of inflammatory changes of the gingiva. Odont Res, 1964; 15: 381-98.

${ }^{29}$ Silness J, Löe H. Periodontal disease in pregnancy, II. Correlation between oral hygiene and periodontal conditions. Acta Odont Scand, 1964; 22: 121-35.

${ }^{30}$ Brand A, Koch G, Lindhe J. Evaluation of gingival fluid measurements. Odontol Rev, 1965; 16: $300-7$.

${ }^{31}$ Oliver RC, Holm-Pedersen P, Löe H. The correlation between clinical scoring, exsudate measurements and microscopic evaluation of inflammation in the gingiva. $J$ Periodont, 1969; 40: 201-9.

32 Rüdin HJ, Overdieck HF, Rateitschak KH. Correlation between sulcus fluid rate and clinical and histological inflammation of the marginal gingiva. Helvet Odont Acta, 1970; 14: 21-26.

${ }^{33}$ Browne SG. B 663 (Geigy)-Further observations on its suspected anti-inflammatory action. Lepr Rev, 1966; 37: 141-5. 


\section{NEWS AND NOTES}

\section{Overseas Medical Aid Trust, Aylesbury, UK}

Philip Sadler has supplied the following information about a Trust near Oxford which has, incidentally, been of enormous value to OXFAM in the ordering and assembly of items for the OXFAM-LEPRA pack of Teaching Materials.

The Overseas Medical Aid Trust is an Aylesbury based charity which sends gifts of medicines, surgical equipment and dressings to small hospitals and clinics in the Third World.

The material we send comes from various sources, some of it free of charge and some we have to buy. Basic pharmaceuticals, for instance, are purchased from ECHO, a non-profit making charitable trust supplying bulk purchase packs of the medicines most suitable for Third World needs, and appropriately designed surgical equipment.

Other useful equipment is sometimes available to us free of charge from the hospital service. As new and improved techniques are introduced, some items of surgical and nursing ware become obsolete. These will still have a very useful life in simple Third World medical practice, and our clinics are delighted to receive them.

Wholesale pharmaceutical distributors and manufacturers are also helpful when they hear about our work, and donate free material or grant us concessionary prices.

The work of collecting, sorting, packing and administration is all done by volunteers working under the supervision of a pharmacist, and the premises we work from are donated to us rent-free.

Expenses therefore are practically nil, and all cash donations received can be converted into practical medical aid. Taking into account free gift material, we are in fact effectively able to send over $£ 2$ worth of aid for every $£ 1$ donated. Total output for the year, calculated at wholesale prices, amounted to $£ 20,012$. Further enquiries: $\mathrm{Mr}$ Philip Sadler, Overseas Medical Aid Trust, 34 High Street, Aylesbury, Bucks, UK.

\section{Back numbers of Leprosy Review required}

We continue to receive a number of requests for complete sets of Leprosy Review and for individual missing numbers. The stocks of back numbers stored by LEPRA are limited. We therefore appeal to anyone who may have an unwanted collection, or odd numbers of the journal, either for donation to a bone fide applicant, or for sale. Within reasonable distance of Oxford or London we would be more than happy to arrange for collection or to negotiate payment for transport by train. Editor.

\section{Closure of the last leprosarium in Australia}

The last leprosarium in Australia situated near Derby in the far north of Western Australia was officially closed on 5 September, 1986. It had been in existence for over 50 years and the patients were nursed there during all that time by the Sisters of St John of God who came specifically to Western Australia to carry out this work.

The number of patients treated in the leprosarium in the 1950's averaged 300, but in the 1980's only a few patients were left and these were there mostly for social reasons.

To mark the closure, besides special ceremonies by staff and ex-patients of the leprosarium itself, a symposium on Hansen's disease was held in Perth on 8 September 1986 under the auspices of the Health Department of Western Australia. The keynote address, 'Future Prospects for the Eradication of Leprosy', was given by Professor M F Lechat from Belgium, a member of the World Health Organisation expert committee on Leprosy.

Other speakers included Associate Professor Clement Boughton, Department of Medicine, University of New South Wales, Dr John Hargrave, Director of The Leprosy Control Programme, Northern Territory, Dr Randolph Spargo, Health Department of Western Australia, Dr Geoff Smith of Ciba-Geigy, and Dr Grace Warren from the Leprosy Mission.

The symposium was well attended and there were over 100 delegates there. All the papers were of extremely high quality and were followed by lively discussions. (Source: Dr J T Cassidy, Director, Communicable Disease Control, 1? Murray Street, Perth, WA 6000, Australia.)

\section{Blister calendar packs for multiple drug therapy in leprosy}

In association with the Government of India, DANIDA is soon to embark on large-scale leprosy control programmes in four different areas of India, using multiple drug therapy, for which 1.7 million blister (calendar) packs are being produced by Pharmanova in Copenhagen. Either in this, or the next number of Leprosy Review', a description will be published of the packs for these programmes for both pauci- and multibacillary patients. Ciba-Geigy in Basle, Switzerland, have also produced packs for both pauci- and multibacillary patients of a smaller, more compact format and these will be on sale from about July 1987. In association with the Ministry of Health in Bangkok, this company is currently organizing a trial of blister (calendar) packs in Thailand, to investigate not only their possible effect on compliance and regularity of attendance, but other advantages which they may have for ordering, despatch, storage, issue to patients and health education (for both patients and families). See also our previous publication on the local development of such packs by the Reverend Wiseman in South Africa (Lepr Rev 1987; 58, 85-7). 